\title{
NUMERICAL SIMULATION OF RIJEKA BAY WATER DYNAMICS FOR MOST COMMON WINDS
}

\begin{abstract}
Summary
The goal of this paper is to quantify the atmospheric influence, i.e. the influence of wind in particular, on the sea dynamics in the Rijeka Bay (Adriatic Sea). This quantification is important for city sewage disposal and dispersion as well as surface pollution dispersion. We compare the effect of jugo (sirocco) and bora winds on a calm period. The resulting simulations show that the bora conveys the surface layer of sea water out of the bay through the Middle and the Great Gate while deep cold water enters the bay through the same gates. The mean vertical upward velocity component close to the coast is about $1 \mathrm{~mm} \mathrm{~s}^{-1}$. This is sufficient to rise cold water near the city of Rijeka to the surface in three hours and to significantly cool the surface layer during summer. For the south-east wind (jugo) the situation is reverse: the warmer surface sea water enters the bay through the Middle and the Great Gate, while the colder bottom sea water exits the bay through the Middle and the Great Gate, accumulating the warmer sea water in the bay. In the case of no wind the surface velocity vectors (at depths of $0.5 \mathrm{~m}$ ) are disordered and do not follow any particular pattern while the movements at $12 \mathrm{~m}, 24 \mathrm{~m}, 36 \mathrm{~m}, 48 \mathrm{~m}$, and $60 \mathrm{~m}$ show dominant flow from the western coast (of the island Krk) toward the eastern coast of the Istrian peninsula.
\end{abstract}

Keywords: coastal sea motion, numerical model, MIKE 3, bora and jugo winds, flow simulation, Rijeka Bay, Adriatic Sea

\section{Introduction}

The knowledge of the atmospheric influence, of which the influence of wind is dominant, on water movement in the Rijeka Bay, which is a part of the northern Adriatic sea, is of great importance. Depending on the movement of the wind, surface pollutants from ship accidents, heat accumulation and higher surface temperatures as well as discharged sewage outfall convection and diffusion are influenced. Therefore, different studies tried to elucidate this influence.

Degobbis et al. [1] discussed hydrographic and hydrodynamic characteristics of the Rijeka Bay on the basis of temperature, salinity and sea current measurements. The prevailing winds were from $\mathrm{NE}\left(41^{\circ}\right)$ and $\mathrm{SW}\left(11^{\circ}\right)$ directions. Based on the measured currents in September and December of 1976, they found that contribution of water exchange from the 
Tihi Kanal (Tihi Channel) (Figure 1.) is negligible in comparison to the exchange through the Great and the Middle Gate. The basic characteristic of their results is that, in winter, water masses enter the Rijeka Bay through the whole water column through the Middle Gate and flow out through the Grate Gate. In winter, there was no stratification in the whole bay. During summer, the authors found a pronounced vertical stratification. The intensity of currents decreased from the surface to the bottom by a factor of 5 in all three channels and in the centre of the bay.

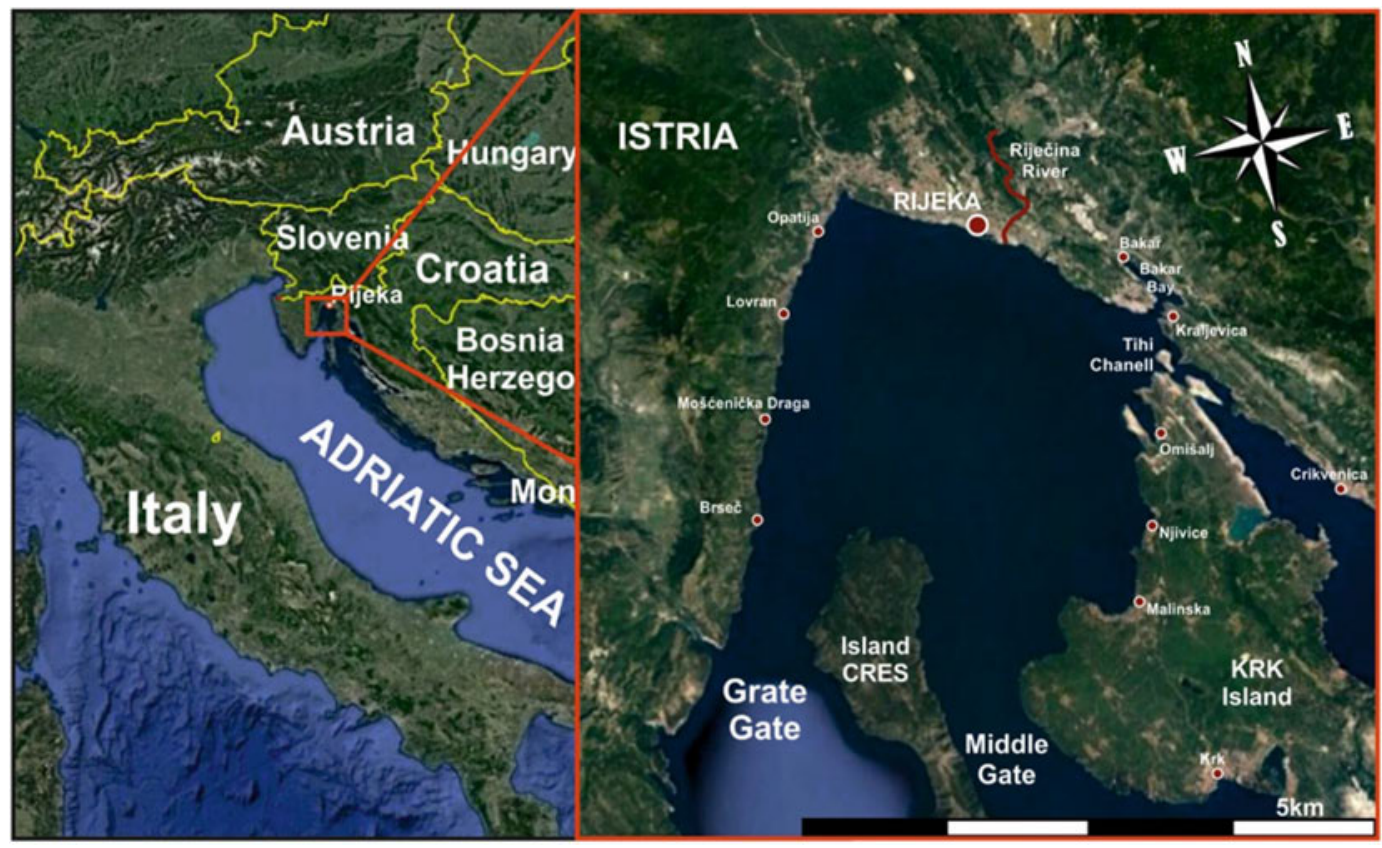

Fig. 1 Left: Adriatic sea, Right: Rijeka Bay

The authors also suggested division of the bay into the following zones according to its hydrographic and hydrodynamic characteristics: the Middle and the Grate Gate channels and the southern part of the bay, the part of the bay next to the island of Krk and the central part of the bay, and the northern part of the bay including the Bakar Bay. The Middle and the Grate Gate channels including the southern part of the bay had the most intensive exchange of water masses and there was a water circulation system working either clockwise or counterclockwise.

Legović and Vučak [2], and Legović [3] found that the exchange rate of the Rijeka Bay water varies seasonally. They identified only two seasons: summer and winter. During summer the exchange takes a clockwise direction with the bulk of the flow in the surface layer above the thermocline. During winter the exchange rate is counterclockwise and it is two to three times stronger than during summer. The resulting exchange time can vary as much as eleven times during the course of a year, from one week to eleven weeks. It is the shortest in the middle of the winter season, and the longest in the summer season.

Legović et al. [4] discussed water dynamics of the Rijeka Bay during summer for two characteristic wind situations, calm weather (no wind) and northerly wind flow. During calm weather the circulation is characterized by a very small flow incoming through the Grate Gate and leaving the bay through the Middle Gate (clockwise). During the northerly wind flow, the circulation around the island of Cres may change the direction, so that the waters enter through the Middle Gate and leave the bay through the Grate Gate (counterclockwise). The northern part of the bay was not much affected in the sense that two gyres still existed and that the pattern of currents was similar to the case when there was no wind. 
Andročec et al. [5] conducted measurements of sea currents, temperature and salinity at the Middle and the Grate Gate in October 2007 and March and May 2008. They simulated movement of water masses in a wider area and suggested to simulate the flow dynamics in the Rijeka Bay using more detailed numerical node resolution, which we did in this paper.

In this paper, numerical simulations using MIKE 3 were conducted for a variety of typical wind directions and intensities starting from 16 July 2008 at $18 \mathrm{~h}$ and ending on 18 July at $6 \mathrm{~h}$ (36 hours altogether). The simulations are forced with water inflow through the sea boundaries: the Middle and the Great Gate, the selected wind, heat flux and moisture on the sea surface. Atmospheric forcing was interpolated from ALADIN with $8 \mathrm{~km}$ spatial resolution and $3 \mathrm{~h}$ temporal resolution.

At the open boundaries, the sea level, salinity and temperature fields were obtained by running ROMS.

We selected two characteristic wind patterns each with two intensities (moderate and strong winds), as most common winds in the bay, and the no wind case.

The calculated velocity vectors for different depths are shown in Figures 4, 5, 6, 7, 8, 9, 10 and 11 for wind intensity of $10 \mathrm{~m} \mathrm{~s}^{-1}$.

\section{Materials and Methods}

\subsection{The area of study}

The modelled area is the Rijeka Bay, which is located between the east coast of the Istrian peninsula, the coast of the city of Rijeka and Kostrena and the islands of Krk and Cres (Figure 1.). The Rijeka Bay area is about $500 \mathrm{~km}^{2}$, and its volume is about $27 \mathrm{~km}^{3}$. The average depth is 60 meters. Geological base of the bay coast is mostly limestone, with some dolomites in the northern part of the bay (Jeftic [6]).

The biggest river entering the Rijeka Bay is Rječina with a length of about $17 \mathrm{~km}$, width near the mouth of $15 \mathrm{~m}$ and flow from 10 to $50 \mathrm{~m}^{3} \mathrm{~s}^{-1}$. Numerous freshwater spills are found along the northern coast and in the Bakar Bay. Their inflow is variable with the most active period in the early spring and late autumn. Prevailing winds blow from north $\left(45^{\circ}\right)$ and southeast $\left(135^{\circ}\right)$. The mean annual air temperature is $13^{\circ} \mathrm{C}$ with an absolute maximum of $36^{\circ}$ and minimum $-12^{\circ} \mathrm{C}$. The annual precipitation is about $1400 \mathrm{~mm}$ with the maximum in autumn and winter. The surface water temperature varies from $10.4^{\circ} \mathrm{C}$ in the winter to $26.6^{\circ} \mathrm{C}$ in the summer time. The deep water temperature reaches its maximum (about $15^{\circ} \mathrm{C}$ ) in October.

The water of the bay in the most part of the water column originates mostly from the middle Adriatic. The water column is well aerated, the oxygen saturation usually varies within the $90-110 \%$ range (Zavodnik and Kovačić, [7]) and is relatively transparent (the Secchi depth is from 15 to $35 \mathrm{~m})$.

\subsection{Models}

The Mike3 software serves for modelling 2D and 3D flows with a free surface in complex oceanographic and coastal regions but also in land flows, as simulations of flood and cracking of dams.

The model consists of continuity, momentum, temperature, salinity and density equations using a turbulence closure. Density does not depend on pressure, just on temperature and salinity.

The local continuity equation is:

$$
\frac{\partial u}{\partial x}+\frac{\partial v}{\partial y}+\frac{\partial w}{\partial z}=S
$$


where $x, y$ and $z$ are Cartesian coordinates, $\mathrm{u}, v$ and $w$ corresponding fluid velocity components, $S$ is a discharge due to point sources. This equation mathematically represents the physical property of water incompressibility.

Two horizontal momentum equations for the $x$ and $y$ component are:

$$
\begin{aligned}
& \frac{\partial u}{\partial t}+\frac{\partial u^{2}}{\partial x}+\frac{\partial v u}{\partial y}+\frac{\partial w u}{\partial z}=f v-g \frac{\partial \eta}{\partial x}-\frac{1}{\rho_{0}} \frac{\partial p_{a}}{\partial x}-\frac{g}{\rho_{0}} \int_{z}^{\eta} \frac{\partial \rho}{\partial x} \mathrm{~d} z+F_{u}+\frac{\partial}{\partial z}\left(v_{t} \frac{\partial u}{\partial z}\right)+u_{s} S \\
& \frac{\partial v}{\partial t}+\frac{\partial v^{2}}{\partial y}+\frac{\partial u v}{\partial x}+\frac{\partial w v}{\partial z}=-f u-g \frac{\partial \eta}{\partial y}-\frac{1}{\rho_{0}} \frac{\partial p_{a}}{\partial y}-\frac{g}{\rho_{0}} \int_{z}^{\eta} \frac{\partial \rho}{\partial y} \mathrm{~d} z+F_{v}+\frac{\partial}{\partial z}\left(v_{t} \frac{\partial v}{\partial z}\right)+v_{s} S
\end{aligned}
$$

where $t$ is the time, $\eta$ is the surface elevation; $d$ is the still water depth; $h=\eta+d$ is the total water depth; $f=2 \Omega \sin \varphi$ is the Coriolis parameter $(\Omega$ is the angular rate of revolution and $\varphi$ the geographic latitude); $g$ is the gravitational acceleration; $\rho$ is the density of water; $v_{t}$ is the vertical turbulent (or eddy) viscosity; $p_{a}$ is the atmospheric pressure; $\rho_{0}$ is the reference density of water. $\mathrm{S}$ is the magnitude of the discharge due to point sources and $\left(u_{s}, v_{s}\right)$ is the velocity by which the water is discharged into the ambient water (Moharir et al., [8]; Warren and Bach, [9]). These two equations mathematically represent Newton's second axiom: the change in velocity is proportional to the resultant force.

The horizontal stress terms are described using a gradient-stress relation, which is simplified to

$$
\begin{aligned}
& F_{u}=\frac{\partial}{\partial x}\left(2 A \frac{\partial u}{\partial x}\right)+\frac{\partial}{\partial y}\left(A\left(\frac{\partial u}{\partial y}+\frac{\partial v}{\partial x}\right)\right) \\
& F_{v}=\frac{\partial}{\partial x}\left(A\left(\frac{\partial u}{\partial y}+\frac{\partial v}{\partial x}\right)\right)+\frac{\partial}{\partial y}\left(2 A \frac{\partial v}{\partial y}\right)
\end{aligned}
$$

where $\mathrm{A}$ is the horizontal eddy viscosity.

Temperature $(T)$ and salinity $(s)$ are modelled by general advection-diffusion equations:

$$
\begin{aligned}
& \frac{\partial T}{\partial t}+\frac{\partial u T}{\partial x}+\frac{\partial v T}{\partial y}+\frac{\partial w T}{\partial z}=F_{T}+\frac{\partial}{\partial z}\left(D_{v} \frac{\partial T}{\partial z}\right)+H+T_{s} S \\
& \frac{\partial s}{\partial t}+\frac{\partial u s}{\partial x}+\frac{\partial v s}{\partial y}+\frac{\partial w s}{\partial z}=F_{s}+\frac{\partial}{\partial z}\left(D_{v} \frac{\partial s}{\partial z}\right)+s_{s} S
\end{aligned}
$$

where $D_{v}$ is the vertical turbulent (eddy) diffusion coefficient. $H$ is a source term due to heat exchange with the atmosphere. $T_{s}$ and $S_{s}$ are the temperature and the salinity of the source. $F_{T}$ and $F_{S}$ are the horizontal diffusion terms defined by:

$$
\begin{aligned}
& F_{T}=\left[\frac{\partial}{\partial x}\left(D_{h} \frac{\partial}{\partial x}\right)+\frac{\partial}{\partial y}\left(D_{h} \frac{\partial}{\partial y}\right)\right] T \\
& F_{S}=\left[\frac{\partial}{\partial x}\left(D_{h} \frac{\partial}{\partial x}\right)+\frac{\partial}{\partial y}\left(D_{h} \frac{\partial}{\partial y}\right)\right] s
\end{aligned}
$$

where $D_{h}$ is the horizontal diffusion coefficient. 
The boundary conditions are defined by the given $2 \mathrm{D}$ velocity and temperature fields at open boundaries, zero velocities at sea bottom, 1D sea height and pressure on free surface. Initial conditions include all unknowns in all mesh points.

Numerical simulations of the Rijeka Bay seawater hydrodynamics were performed using MIKE 3 for a variety of typical wind directions and intensities starting from 16 July 2008 at $18 \mathrm{~h}$ and ending 18 July 2008 at $6 \mathrm{~h}$ with the time step of 20 seconds.

The simulations were forced with water inflow through the sea boundaries: the Middle and the Great Gate, the selected wind, heat flux and moisture on the sea surface. Tihi Kanal was not treated as open boundary due to small inflow. Atmospheric forcing was used from ALADIN (Tudor et al. [10]), with $8 \mathrm{~km}$ spatial resolution and $3 \mathrm{~h}$ temporal resolution (which is regularly employed for meteorological modelling of atmospheric flow).

At the open boundaries the sea levels, 2D velocity, salinity and temperature fields were obtained by running ROMS (Shchepetkin-and Mcwilliams, [11] 2005) and are taken from Andročec et al. [5].

We selected two characteristic wind patterns each with two intensities (moderate and strong winds) and no wind case, as most common wind states in the bay. The surface sea velocity vector dynamics for zero wind, bora $\left(45^{\circ}\right)$ and jugo $\left(135^{\circ}\right)$ and two intensities $(10$ and $30 \mathrm{~m} \mathrm{~s}^{-1}$ ), for one month period starting from 16 July 2008, are given in supplementary movies.

The calculated velocity fields at $0 \mathrm{~m}, 12 \mathrm{~m}, 24 \mathrm{~m}, 36 \mathrm{~m}, 48 \mathrm{~m}$, and $60 \mathrm{~m}$ depths for the wind intensity of $10 \mathrm{~m} \mathrm{~s}^{-1}$ at one time instance, on 17 July 2008 at 10,5h are shown below.

The influence of the finite difference mesh size on the simulation results is analyzed using three meshes: the coarse, the finer and the finest mesh.

The coarse mesh has a step size (the distance between adjacent nodes) of $165 \mathrm{~m}$ in the equatorial and $232 \mathrm{~m}$ in the meridional direction (Figure 2). The finer mesh has about three times smaller step size, $55 \mathrm{~m}$ in the equatorial and $77.33 \mathrm{~m}$ in the meridional direction. The mesh is nested in the coarse mesh and covers only the northern part of the Rijeka Bay. The finest mesh is nested in the finer mesh and it is three times finer, amounting to $18.33 \mathrm{~m}$ and $25.77 \mathrm{~m}$ in the equatorial and meridional directions, respectively. The finest mesh covers a part near the coast of the city of Rijeka sewage discharge. The vertical mesh step is the same for the three meshes and equals $2 \mathrm{~m}$.

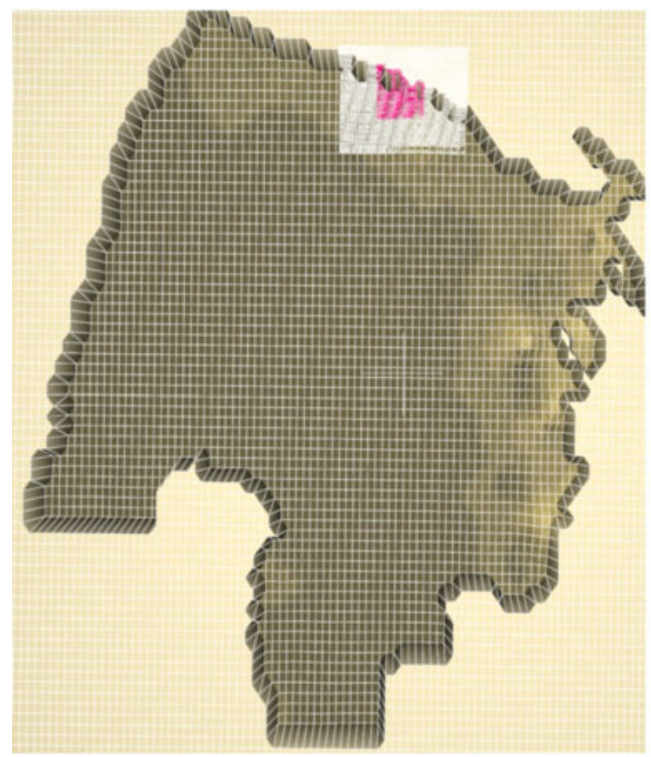

Fig. 2 Three finite difference meshes: coarse - white lines on dark brown background (165m x 232m)

(every other line is displayed), finer mesh is in white $(55 \mathrm{~m} \mathrm{x} 77.33 \mathrm{~m})$ and finest mesh is denoted in pink (18.33m X $25.77 \mathrm{~m})$ 
It was not necessary to further reduce the size of the mesh to the fourth level because with the second and the third level of the mesh resolution the rapid convergence has already been achieved.

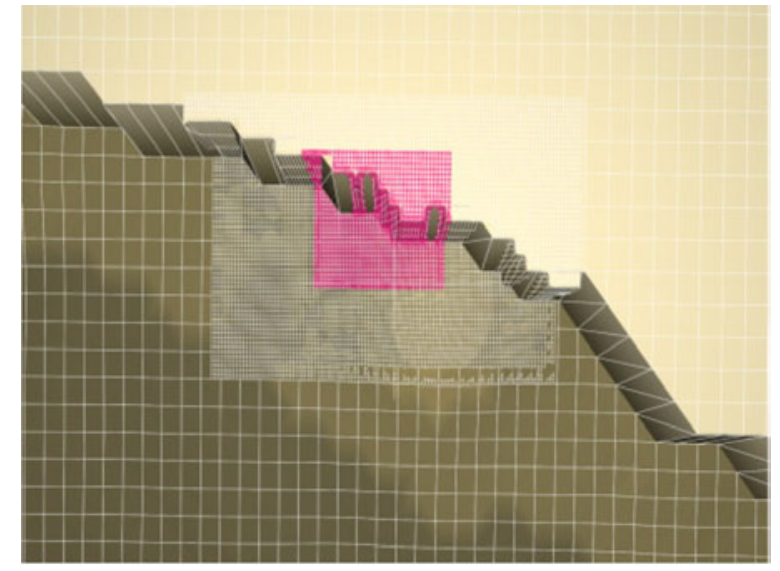

Fig. 3 Enlarged detail of all three meshes near sewage discharge of Rijeka

\section{Results and discussion}

\subsection{Hydrodynamics}

In this part, an insight into the results and analysis of hydrodynamics simulations are presented in the form of velocity field, salinity and temperature in the whole Rijeka Bay.

The start time of the simulation was 16 July 2008 at $18 \mathrm{~h}$, which corresponds to the start of the period when meteorological and hydrographic data were available.

The flow forcing is achieved by interpolation of heat flow and humidity obtained as output fields from the simulation of atmosphere dynamics by the ALADIN program. ALADIN uses $8 \mathrm{~km}$ horizontal surface resolution and 3 hour temporal resolution, and gives a set of wind speeds and directions on the sea surface.

On the open sea boundaries, at the Grate and the Middle gate the following boundary conditions are given for all instants of simulation: 1D sea level, 2D salinity and temperature fields interpolated from the ROMS software simulations (Wilkin et al. [12]) with spatial resolution of two kilometers presented in Andročec et al. [5].

For the two wind directions of the winds bora NE $\left(45^{\circ}\right)$ and for jugo SE $\left(135^{\circ}\right)$ two constant intensities of wind speed were chosen, i.e. $10 \mathrm{~m} \mathrm{~s}^{-1}$ and $30 \mathrm{~m} \mathrm{~s}^{-1}$, which correspond to moderate and strong winds.

\subsection{The case of no wind}

Figures 4 and 5 show the velocity field in the Rijeka Bay for the case without wind and the velocity vectors on the coarse grid at different depths: $0 \mathrm{~m}, 12 \mathrm{~m}, 24 \mathrm{~m}, 36 \mathrm{~m}, 48 \mathrm{~m}$, and $60 \mathrm{~m}$ at the moment 16.5 hours after the simulation started.

For the case without wind at all depths $(0 \mathrm{~m}, 12 \mathrm{~m}, 24 \mathrm{~m}, 36 \mathrm{~m}, 48 \mathrm{~m}$, and $60 \mathrm{~m})$ current vectors are disordered, they do not follow some particular pattern. Since water is partially entering the Rijeka Bay through the Great and the Middle Gate, as well as leaving it through the same gates, and there is no wind forcing on the surface, the disordered velocity field results.

At greater depths $(12 \mathrm{~m}, 24 \mathrm{~m}, 36 \mathrm{~m}, 48 \mathrm{~m}$, and $60 \mathrm{~m})$ there exists one current pattern from the direction of the Middle Gate (between the islands of Krk and Cres), which turns around the northern tip of the island of Cres, where it works as a local vortex, and exits through the Great Gate. 

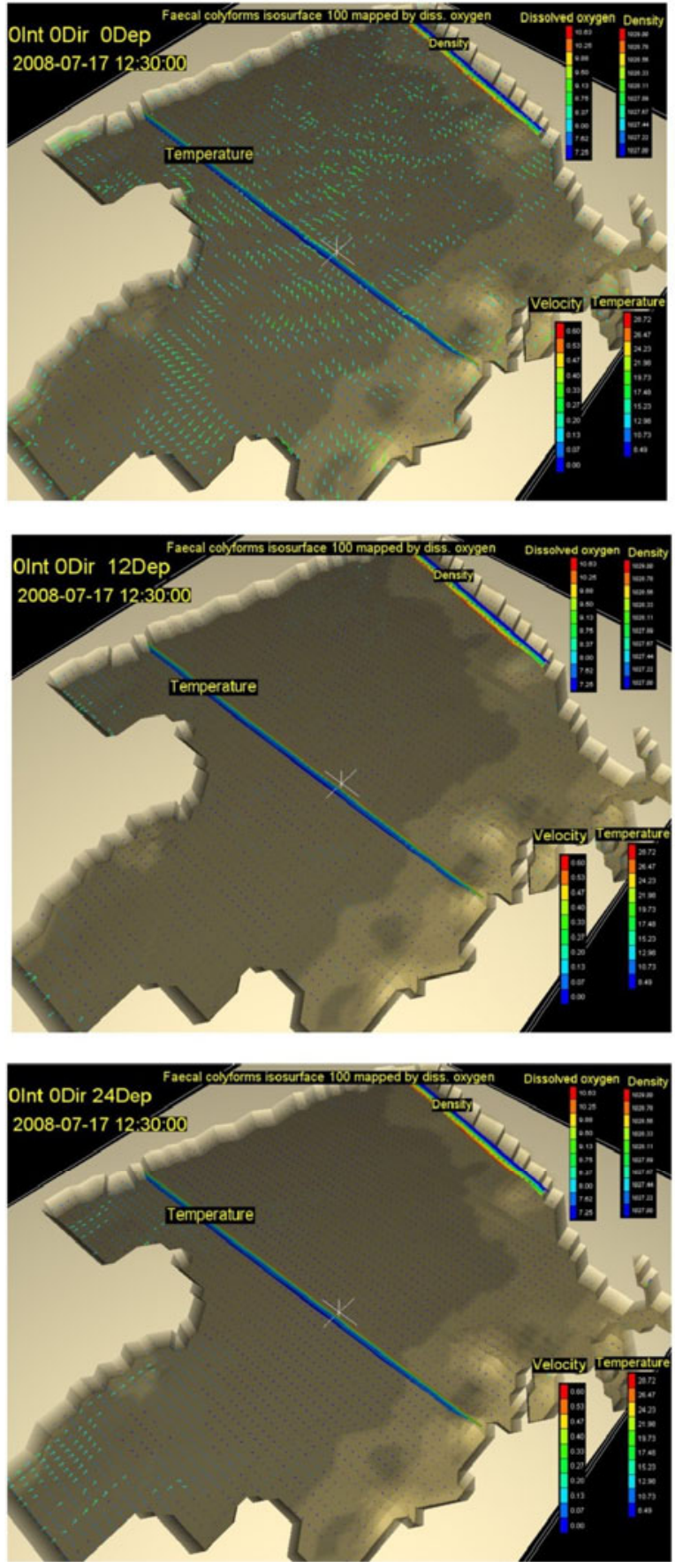

Fig. 4 Current vectors on the surface (top), at a depth of $12 \mathrm{~m}$ (middle) and $24 \mathrm{~m}$ (below)

with a vertical profile of temperature and density at 16.5 th hour of no wind forcing
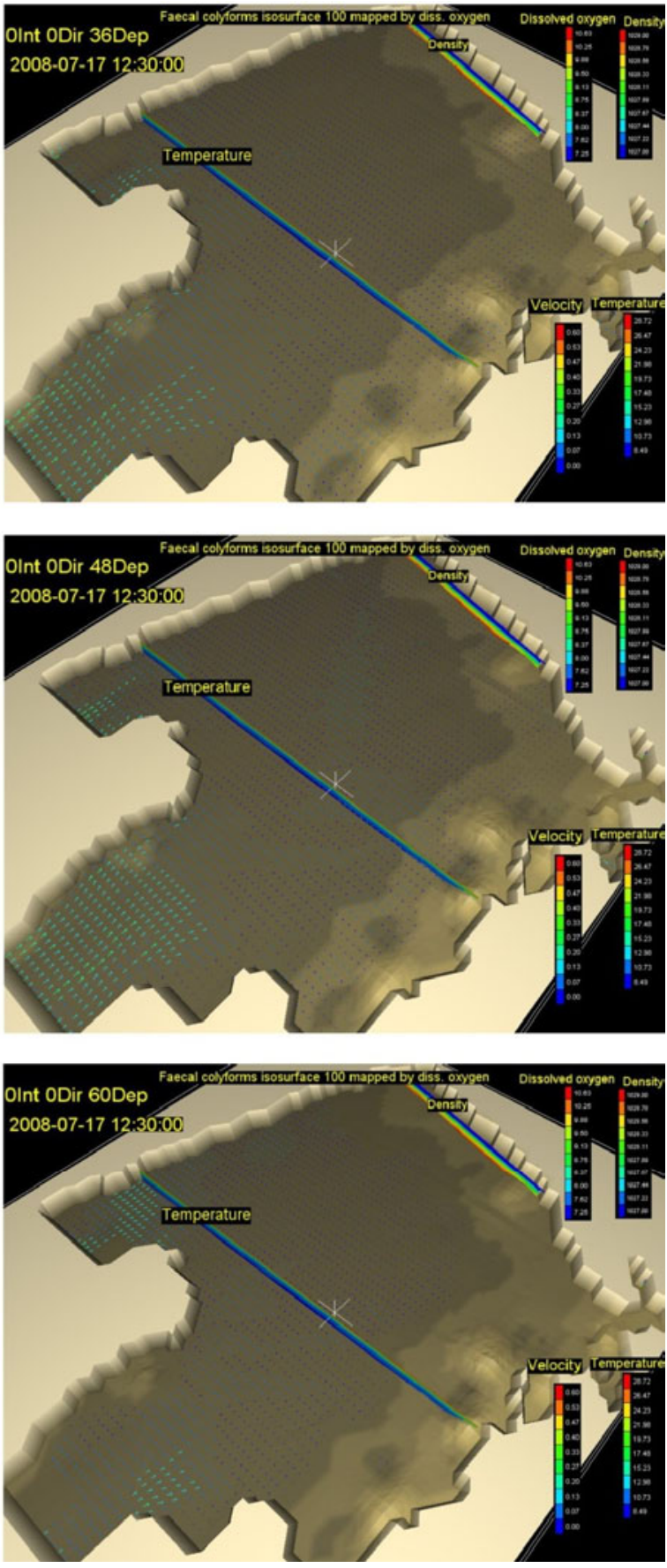

Fig. 5 Current vectors at a depth of $36 \mathrm{~m}$ (top), $48 \mathrm{~m}$ (middle) and $60 \mathrm{~m}$ (below) with a vertical profile of temperature and density at 16.5 th hour for case of no wind forcing

\subsection{The case of jugo wind}

Figures 6, 7 and 8 show the velocity field in the Rijeka Bay for a moderate wind forcing with intensity of $10 \mathrm{~m} \mathrm{~s}^{-1}$ from the direction of $135^{\circ}$ degrees (SE). The velocity vectors at different depths, i.e. $0 \mathrm{~m}, 12 \mathrm{~m}, 24 \mathrm{~m}, 36 \mathrm{~m}, 48 \mathrm{~m}$, and $60 \mathrm{~m}$, and the moment of 16.5 hours after the forcing started, originate from the simulation using the coarse grid. The dominant current is a surface current from the direction of the Middle Gate (between the islands of Krk and Cres), which turns around the northern tip of the island of Cres, where it works as a local 
vortex, and exits through the Great Gate. The speeds in the remaining part of the bay are much smaller than the speed in the mainstream.

This pattern is repeated for other depths, with smaller velocities at a greater depth. Along the northern coast, including the location near Rijeka velocities are small at all depths and have generally the direction parallel to the coast, east to west or vice versa, west-east.
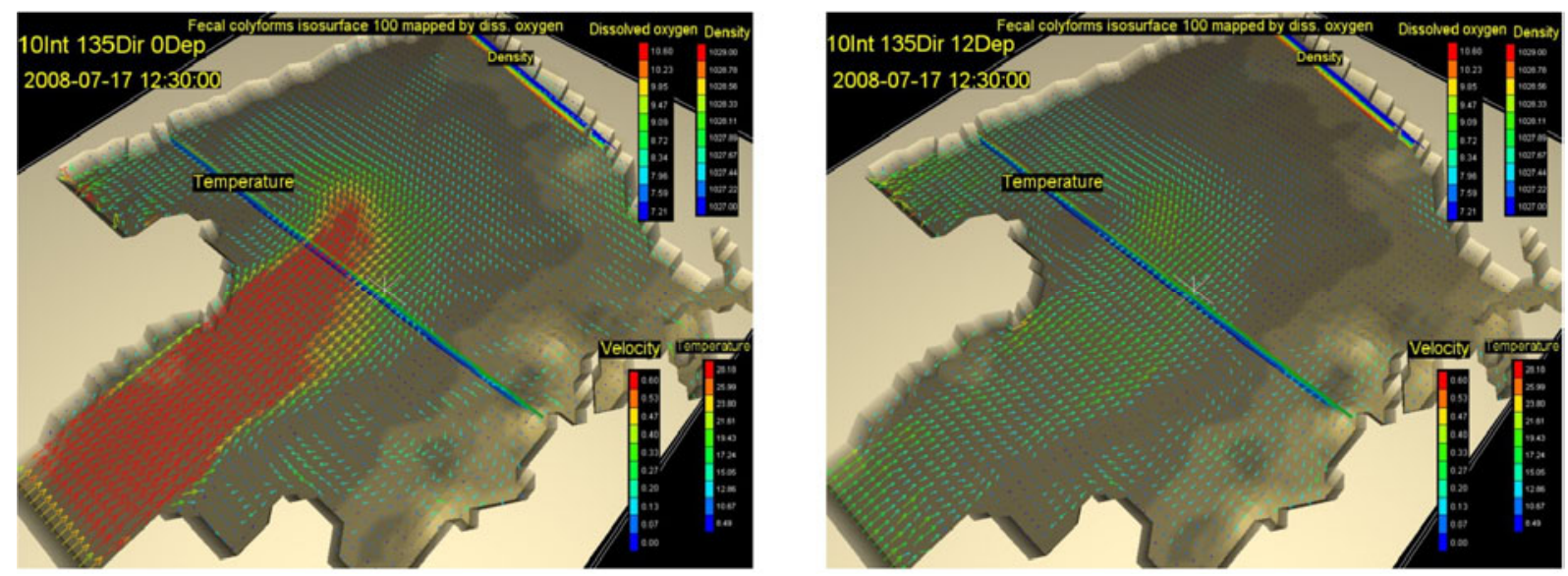

Fig. 6 Current vectors on the surface (left) and at a depth of $12 \mathrm{~m}$ (right) with a vertical profile of temperature and density at 16.5 th hour for wind intensity $10 \mathrm{~m} \mathrm{~s}^{-1}$ and direction of 135 degrees
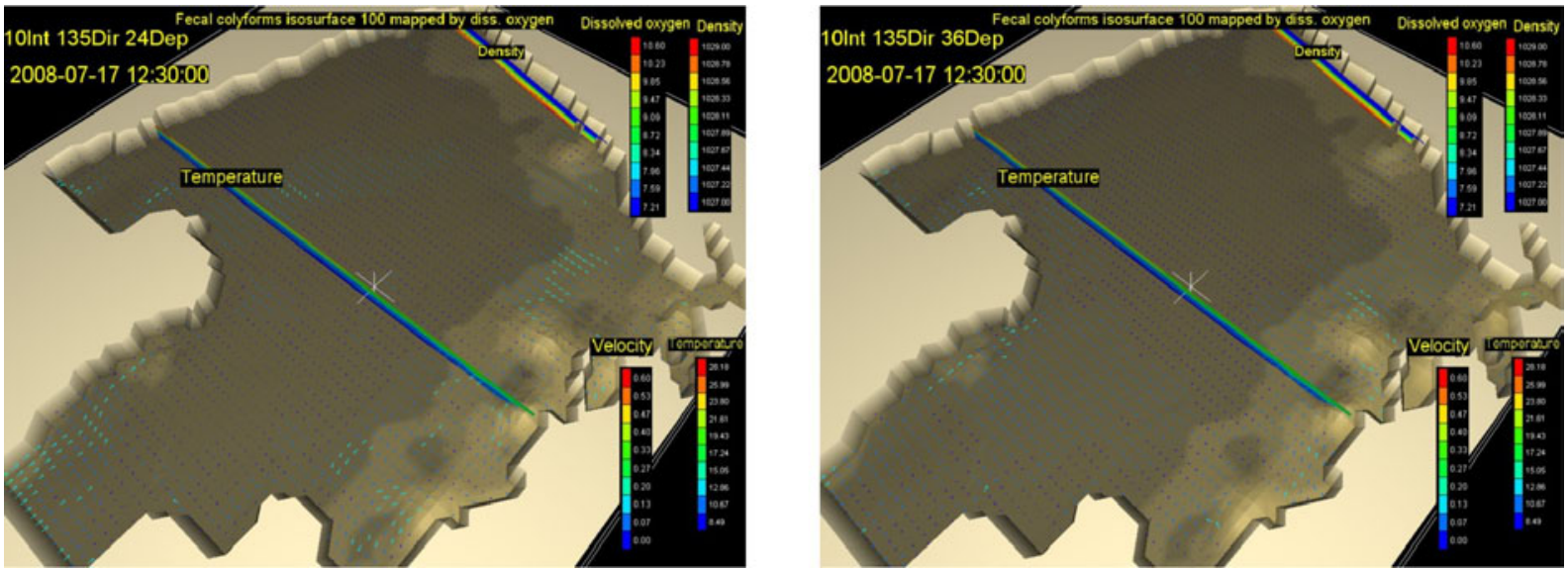

Fig. 7 Current vectors at a depth of $24 \mathrm{~m}$ (left) and at $36 \mathrm{~m}$ (right) with a vertical profile of temperature and density at 16.5 th hour for wind intensity $10 \mathrm{~m} \mathrm{~s}^{-1}$ and direction of 135 degrees
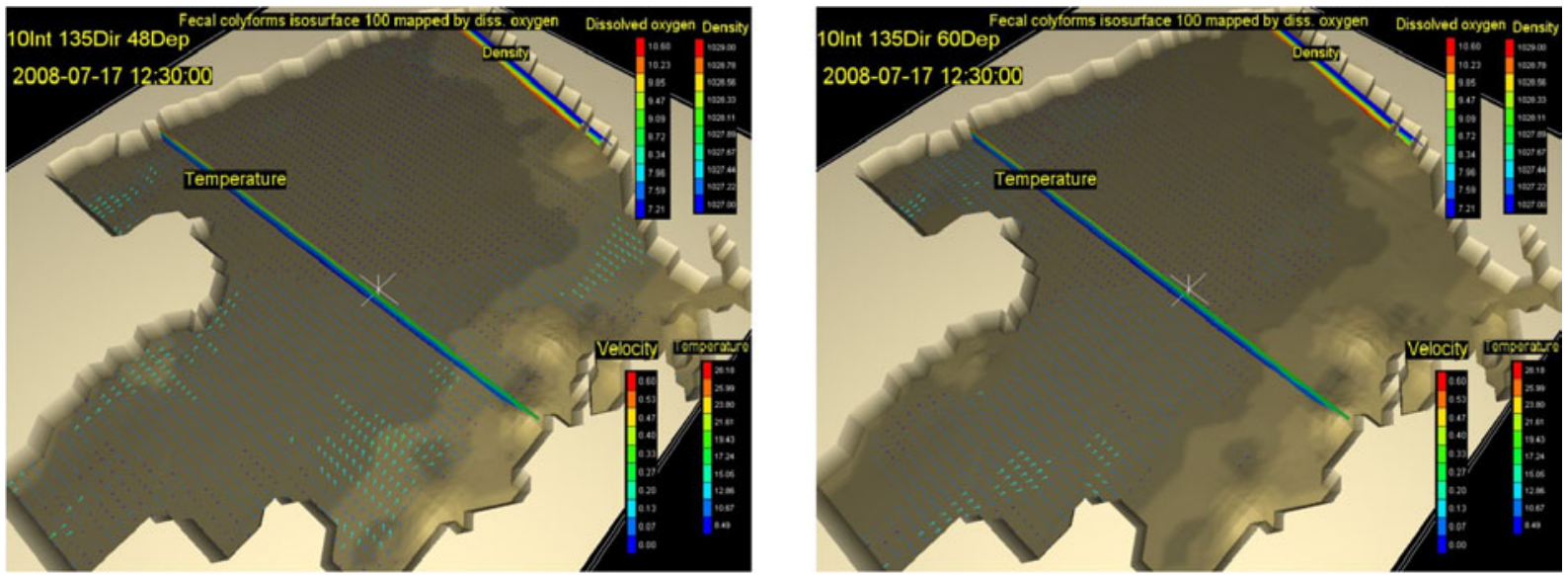

Fig. 8 Current vectors at a depth of $48 \mathrm{~m}$ (left) and at $60 \mathrm{~m}$ (right) with a vertical profile of temperature and density at 16.5 th hour for wind intensity $10 \mathrm{~m} \mathrm{~s}^{-1}$ and direction of 135 degrees 


\subsection{The case of bora wind}

Figures 9, 10 and 11 show the simulated velocity field in the Rijeka Bay for the moderate forcing wind, intensity of $10 \mathrm{~m} \mathrm{~s}^{-1}$, from the direction of 45 degrees (bora).

The following six images shows the current vectors on the coarse grid at depths of $0 \mathrm{~m}$, $12 \mathrm{~m}, 24 \mathrm{~m}, 36 \mathrm{~m}, 48 \mathrm{~m}$, and $60 \mathrm{~m}$ at the moment 16.5 hours after the forcing started.
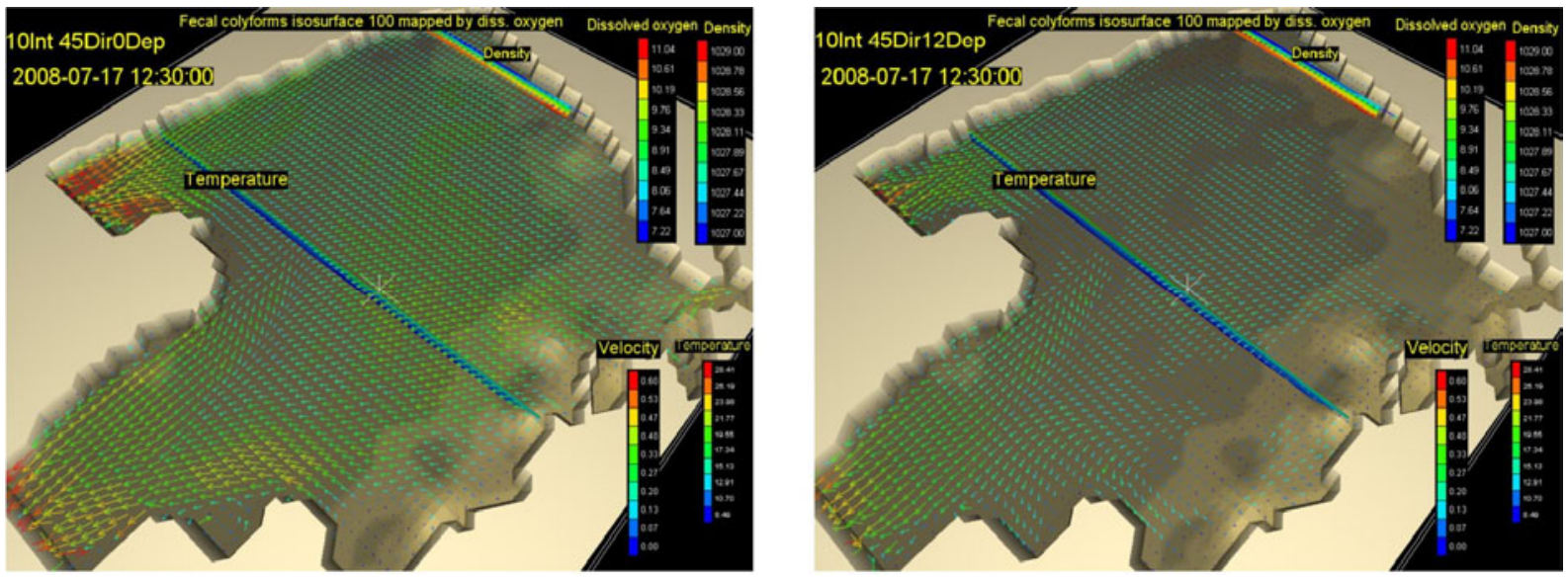

Fig. 9 Current vectors on the surface (left) and at a depth of $12 \mathrm{~m}$ (right) with a vertical profile of temperature and density at 16.5 th hour for wind intensity $10 \mathrm{~m} \mathrm{~s}^{-1}$ and direction of 45 degrees
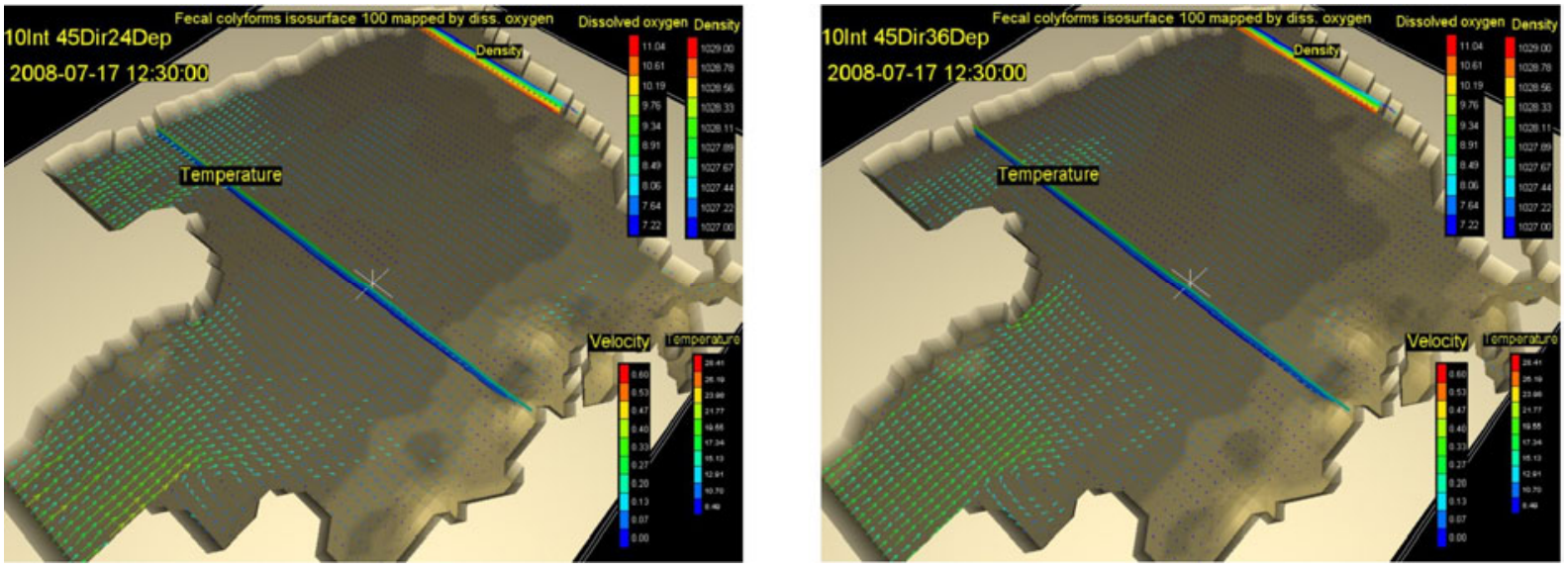

Fig. 10 Current vectors at a depth of $24 \mathrm{~m}$ (left) and at $36 \mathrm{~m}$ (right) with a vertical profile of temperature and density at 16.5 th hour for wind intensity $10 \mathrm{~m} \mathrm{~s}^{-1}$ and direction of 45 degrees
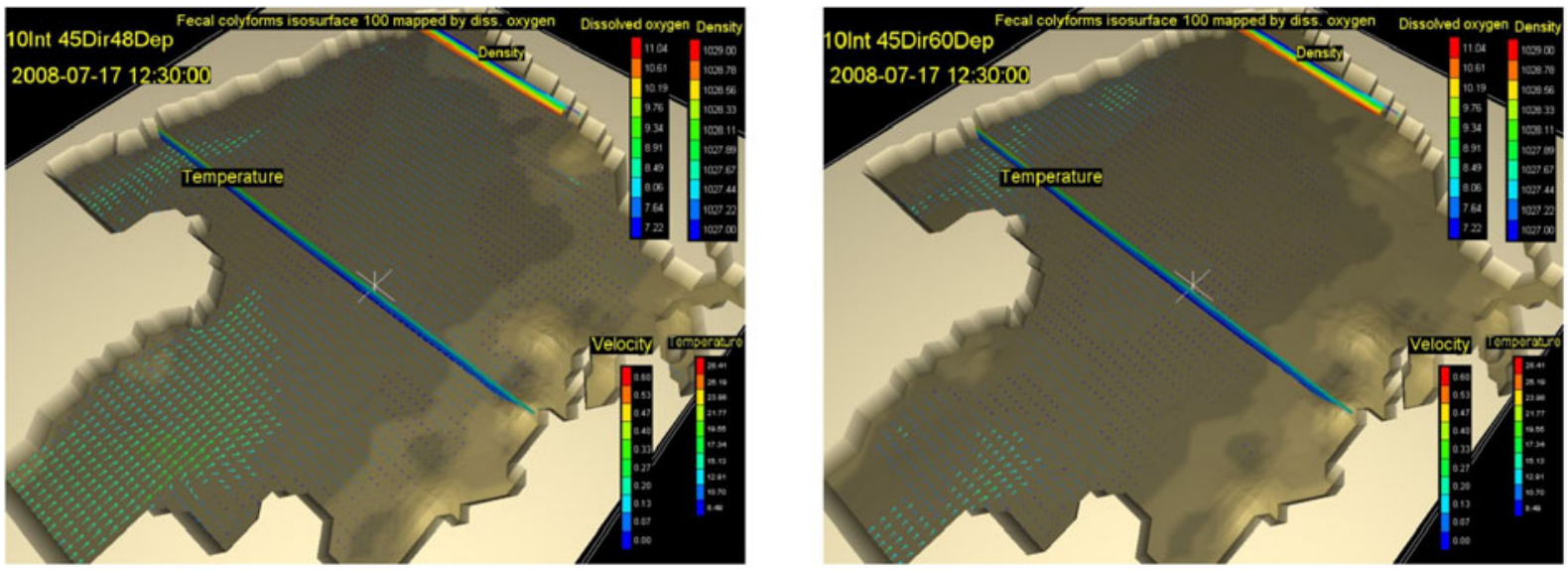

Fig. 11 Current vectors at a depth of $48 \mathrm{~m}$ (left) and at $60 \mathrm{~m}$ (right) with a vertical profile of temperature and density at 16.5 th hour for wind intensity $10 \mathrm{~m} \mathrm{~s}^{-1}$ and direction of 45 degrees 
The dominant surface current at the $0 \mathrm{~m}$ and $12 \mathrm{~m}$ depth has the north-east direction from the northern coast of the bay to the Middle and the Great Gate, so entire surface waters exit from the Rijeka Bay through both gates.

The direction of currents at lower layers of the bay is opposite: at the depths of $24 \mathrm{~m}$, $36 \mathrm{~m}, 48 \mathrm{~m}$ and $60 \mathrm{~m}$ the water enters the Rijeka Bay through the Middle and the Great Gate. Speeds along the northern coast of the bay, near the city of Rijeka are low at all depths and are generally in the direction parallel to the coast, east to west or vice versa west-east.

In all cases of wind simulation, the mean vertical velocity component close to the coast is about $1 \mathrm{~mm} \mathrm{~s}^{-1}$. This is high enough to raise cold water in 3 hours and for the surface coastal sea to be significantly cooled by bora during summer.

\section{Conclusions}

In this paper, a quantification of the atmospheric influence, primarily the influence of wind on the sea dynamics in the Rijeka bay (part of the Adriatic Sea) is given. The results are important for city sewage disposal and dispersion as well as surface pollution dispersion. The commercial software MIKE 3 was used for the 3D water velocities simulation on three different mesh sizes. Boundary and initial conditions were interpolated from either the measured values or from the results obtained by running ROMS (on wider area of the Adriatic sea) and taken from Andročec et al. [5].

The resulting simulations of the sea motion in the Rijeka bay show the following: the bora wind conveys surface water layer out of the bay through the Middle and the Great Gate while deep cold layers of water enter the bay through both the Middle and the Great Gate.

The simulations show for all winds that the mean vertical velocity component close to coast is about $1 \mathrm{~mm} \mathrm{~s}^{-1}$. This is high enough to raise cold water below the thermocline in 3 hours and significantly cool the surface coastal sea during summer. For the south wind (jugo) the situation is reversed; the warm surface sea layer enters the bay through the Middle and the Great Gate, while cold bottom sea layers exit the bay, accumulating warmer sea water on the surface layer in the bay.

For the case without wind the surface velocity vectors are disordered i.e. they do not follow a particular pattern. At greater depths $(12 \mathrm{~m}, 24 \mathrm{~m}, 36 \mathrm{~m}, 48 \mathrm{~m}$, and $60 \mathrm{~m})$ one current pattern is from the direction of the Middle Gate (between the islands of Krk and Cres), which turns around the northern tip of the island of Cres, where it works as a local vortex, and exits through the Great Gate.

The comparison of water dynamics of the case with no wind with the periods with the bora (45, $10 \mathrm{~m} \mathrm{~s}^{-1}$ intensity) and jugo winds $\left(135^{\circ}, 10 \mathrm{~m} \mathrm{~s}^{-1}\right.$ intensity) shows that when there is no wind the speeds are lower at all depths, than in the case of the periods with the bora and jugo winds. When there is no wind there is no particular current pattern on the surface, while in the periods with the bora and jugo winds two characteristic surface patterns exist.

Considering the simulated dynamics of water motions, one can conclude that the jugo wind will accumulate surface pollutants in the bay, while the bora will tend to convey it out of the bay.

The present work presents a basis for modelling city sewage disposal diffusion and dispersion from the Delta sewage outflow, which will be dealt with in the future paper.

\section{REFERENCES}

[1] Degobbis, D., Ilić, D., Jeftić, L., Nozina, I., Smodlaka N., Vučak, Z. Hydrographic and hydrodinamic characteristics of Rijeka Bay. IV ${ }^{e s}$ Journées Ėtud. Pollutios. 1978, 551-554. Antalya. C.I.E.S.M. 
[2] Legović ,T., Vučak, Z. Kinematics of water exchange in the Rijeka Bay. Thalassia Jugoslavica 17 1981, $3 / 4,155-175$.

[3] Legović, T. Water exchange between a coastal basin and the adjacent sea with an application to the Rijeka Bay. Deep Sea Research, 29 1982, 999-1012.

[4] Legović, T., Limić, N., Sekulić, B. Reconstruction of a Concetration Field in a Coastal Sea, Estuarine, Coastal and Shelf Science, 29 1989, 217-231.

[5] Andročec, V., Beg Paklar, G., Dadić, V., Đakovac, T., Grbec, B., Janeković, I., Krstulović, N., Kušpilić, G., Leder, N., Lončar, G., Marasović, I., Precali, R., Šolić, M. The Adriatic Sea monitoring program Final Report, Project No. M-C-1, Part C1: Strengthening of coastal water monitoring network, Ministry of environmental Protection, Physical Planning and Construction of Republic of Croatia, Zagreb 2009

[6] Jeftić, L. Ekološka istraživanja Riječkog zaljeva, Pomorski zbornik, 20 1982, 505-520.

[7] Zavodnik, D., Kovačić, M. Indeks of marine fauna in Rijeka Bay (Adriatic Sea, Croatia), Natura Croatica, 9 2000, 4, 297-379.

[8] Moharir, R.V., Khairnar, K., Paunikar, W.N. MIKE 3 as a modeling tool for flow characterization: A review of applications on water bodies, International Journal of Advanced Studies in Computer Science \& Engineering, 3 2014, 3, 32-43.

[9] Warren, I.R., Bach, H.K.: MIKE 21 a modelling system for estuaries, coastal waters and seas, Environmental Software, 7 1992, 4, 229-240.

[10] Tudor, M., Ivatek-Šahdan, S., Stanešić, A., Horvath, K., Bajić, A. Forecasting Weather in Croatia Using ALADIN Numerical Weather Prediction Model, Climate Change and Regional/Local Responses, Dr Pallav Ray (Ed.), 2013, InTech, https://doi.org/10.5772/55698.

[11] Shchepetkin, A.F. Mcwilliams, J.C. The Regional Ocean Modeling System: a split explicit, free-surface, topography following coordinates ocean model, Ocean Modell., 9 2005, 347-404.

[12] Wilkin, J.L., Arango H.G., Haidvogel, D.B., Lichtenwalner, C.S., Glenn, S.M., Hedström A regional ocean modelling system for the long term ecosystem observatory, Journal of geophysical research 110 2005, C06S91.

Submitted: $\quad 22.11 .2017$

Accepted: $\quad$ 16.3.2018
Iva Mrša Haber

Department of Quantitative Economics, Faculty of tourism and hospitality menagement, University of Rijeka, Primorska 42, 51410 Opatija, Croatia Tarzan Legović Division for Marine and Environmental Research, Ruđer Bošković Institute, Bijenička cesta 54, 10000 Zagreb, Croatia Marijan Cukrov Intermodal Transport Cluster, Trpimirova 2, 51000 Rijeka, Croatia 